\title{
Angiotensin II receptor blockade is associated with preserved muscle strength in chronic hemodialysis patients
}

Yu-Li Lin ${ }^{1,2}$, Shu-Yuan Chen ${ }^{2}$, Yu-Hsien Lai ${ }^{1}$, Chih-Hsien Wang ${ }^{1}$, Chiu-Huang Kuo ${ }^{1}$, Hung-Hsiang Liou ${ }^{3 *}$ and Bang-Gee $\mathrm{Hsu}^{1,4^{*}}$ (D)

\begin{abstract}
Background: Sarcopenia, defined as low muscle mass and strength, is highly prevalent in patients undergoing chronic hemodialysis (HD). However, muscle function and muscle mass do not share the same clinical relevance. In fact, muscle strength was more closely associated with the risk of mortality in chronic HD patients than was muscle mass. Therefore, to identify the risk factors of muscle weakness is vital. Angiotensin II overexpression had been recognized to impair skeletal muscle strength. Accordingly, angiotensin II receptor blockers (ARBs) potentially possess a muscle protective effect. This cross-sectional study aimed to identify the factors associated with low muscle strength and to explore the relationship between ARB use and muscle strength in chronic HD patients.
\end{abstract}

Methods: A total of 120 chronic HD patients, aged $63.3 \pm 13.2$ years, were included in this study. Basic characteristics, handgrip strength (HGS), body composition, and nutritional status were assessed, and blood samples for biochemical tests were obtained. We divided these participants into normal- and low HGS groups according to the consensus of the European Working Group on Sarcopenia in Older People (EWGSOP).

Results: We observed that 78 (65.0\%) patients had low HGS. In our cohort, we found that height $(r=0.653 ; P<0.001)$, weight $(r=0.496 ; P<0.001)$, body mass index $(r=0.215 ; P=0.020)$, skeletal muscle index $(r=0.562 ; P<0.001)$, albumin $(r=0.197 ; P=0.032)$, and serum creatinine $(r=0.544 ; P<0.001)$ were positively and age $(r=-0.506 ; P<0.001)$, subjective global assessment (SGA) score $(r=-0.392 ; P<0.001)$, fractional clearance index for urea (Kt/ $\mathrm{N})$ $(r=-0.404 ; \mathrm{P}<0.001)$ and urea reduction ratio (URR) $(r=-0.459 ; P<0.001)$ were negatively correlated with HGS. According to our analysis, age (Odds ratio, $\mathrm{OR}=1.11,95 \%$ confidence interval, $95 \% \mathrm{Cl}=1.05-1.17, P<0.001$ ), HD duration $(\mathrm{OR}=1.01,95 \% \mathrm{Cl}=1.00-1.02, P=0.010)$, diabetes $(\mathrm{OR}=13.33,95 \% \mathrm{Cl}=3.45-51.53, P<0.001)$, $\mathrm{Kt} / \mathrm{O}(\mathrm{OR}=1.61,95 \% \mathrm{Cl}=1.06-2.46, P=0.027)$, and SGA score $(\mathrm{OR}=1.19,95 \% \mathrm{Cl}=1.03-1.38, P=0.017)$ were regarded as independent predictors of low HGS. In contrast, $A R B$ use $(\mathrm{OR}=0.25,95 \% \mathrm{Cl}=0.07-0.93, P=0.039)$ was independently associated with preserved HGS in chronic HD patients, after adjustment for multiple confounding factors.

Conclusions: Our study is the first report in chronic HD patients to indicate a potentially protective effect of ARB on muscle strength. However, further longitudinal follow-up and intervention studies are needed to confirm this finding.

Keywords: Muscle strength, Angiotensin II receptor blockers, Hemodialysis

\footnotetext{
* Correspondence: hh258527@ms23.hinet.net; gee.lily@msa.hinet.net

${ }^{3}$ Division of Nephrology, Department of Internal Medicine, Hsin-Jen Hospital, New Taipei City, Taiwan

'Division of Nephrology, Buddhist Tzu Chi General Hospital, Hualien, Taiwan

Full list of author information is available at the end of the article
}

(c) The Author(s). 2019 Open Access This article is distributed under the terms of the Creative Commons Attribution 4.0 International License (http://creativecommons.org/licenses/by/4.0/), which permits unrestricted use, distribution, and reproduction in any medium, provided you give appropriate credit to the original author(s) and the source, provide a link to the Creative Commons license, and indicate if changes were made. The Creative Commons Public Domain Dedication waiver (http://creativecommons.org/publicdomain/zero/1.0/) applies to the data made available in this article, unless otherwise stated. 


\section{Background}

Sarcopenia, a syndrome characterized by progressive and generalized loss of skeletal muscle mass and strength defined by the consensus of the European Working Group on Sarcopenia in Older People (EWGSOP), leads to impaired activities of daily living, poor quality of life, and enhanced risk of adverse outcomes, such as falls, bone fractures, disabilities, and death [1-4]. In patients with end-stage renal disease (ESRD), sarcopenia has a high prevalence ranging from 14 to $63 \%$ [5-7]. Interestingly, muscle strength and muscle mass, two entities of sarcopenia, do not share the same clinical relevance [8]. In fact, muscle mass is not the only determinant of muscle strength. During the aging process, the decline of muscle strength is much more rapid than the loss of muscle mass [9]. In contrast to reports on the general population, a recent large-scale study delineated that neither low muscle mass nor sarcopenia was significantly associated with mortality in chronic hemodialysis (HD) patients [10], whereas several studies demonstrated a significant association between low muscle strength and high mortality in dialysis patients [11-13]. These findings indicate that muscle strength and muscle mass revealed different impacts on mortality in patients with chronic HD. Therefore, to identify the risk factors of muscle weakness is vital.

Overexpression of angiotensin II has been hypothesized to exert negative impacts, via inhibition of IGF-1/ insulin/PI3K/Alt intracellular signaling, downregulation of phospho-Akt, and activation of caspase-3 in skeletal muscle, on skeletal muscle homeostasis [14-16]. Infusion of angiotensin II in rats was observed to induce muscle proteolysis [17], a finding which suggested that angiotensin II receptor blocker (ARB) use may have the potential to prevent muscle strength loss. In fact, additional animal studies confirmed the protective effects of $\mathrm{ARB}$ on muscle function and mass loss [18-22]. However, the impact of ARB use on skeletal muscle in patients with chronic kidney disease has never been reported and remains to be clarified.

The purpose of our study aimed to identify the factors that contribute to low muscle strength and to explore the relationship between ARB use and muscle strength in chronic HD patients.

\section{Methods}

\section{Patients}

This is a single-center, cross-sectional study of prevalent HD patients conducted between January and December of 2015. Patients who were older than 20 years and had undergone $\mathrm{HD}$ for at least 3 months at a medical center in Hualien were recruited, and patients with malignancy, stroke, acute infection, and amputated limbs, as well as those who were bed-ridden, were excluded from the study. We collected a drug use history by a review of medical records, which included ARB, calcium channel blockers, $\beta$-blockers, statins, or fibrates. Diabetes mellitus (DM) was defined on the basis of history or anti-diabetic drugs use, while hypertension was defined on the basis of history or receiving anti-hypertensive agents. Blood pressure was measured before the HD session, using standard mercury sphygmomanometers. All participants signed an informed consent form approved by the Institutional Review Board of Tzu Chi Hospital.

\section{Low muscle strength definition}

Muscle strength was assessed by measuring handgrip strength (HGS), an established method to assess skeletal muscle function in patients with chronic kidney disease [23]. We measured HGS on the arm without vascular access in our patients, using a Jamar Plus Digital Hand Dynamometer (SI Instruments Pty Ltd., Hilton, Australia) with a precision of $1 \mathrm{~kg}(\mathrm{~kg})$. Patients were instructed to hold the dynamometer in the chosen hand and to squeeze it as hard as they could, with the arm at right angles and the elbow by the side of the body in the upright position. Each measurement was repeated three times, with a rest period of $1 \mathrm{~min}$ between measurements, and an average value was recorded. All the measurements of HGS were carried out by the same trained operator before each $\mathrm{HD}$ session. According to the EWGSOP criteria, low handgrip strength was defined as HGS less than $30 \mathrm{~kg}$ for men and $20 \mathrm{~kg}$ for women in the ESRD population $[4,5,7,8,24]$.

\section{Body composition measurements}

Height and post-HD body weight were measured to calculate body mass index (BMI) according to the equation post-HD body weight $(\mathrm{kg})$ divided by height (square meters). Skeletal muscle mass was assessed via leg-to-leg bioimpedance analysis by using a portable whole-body bioelectrical impedance device (Tanita BC $706 \mathrm{~dB}$, Tanita Corporation, Tokyo, Japan) with the patient in the standing position before each HD session. Skeletal muscle index (SMI) was calculated as skeletal muscle mass/ height $^{2}\left(\mathrm{~kg} / \mathrm{m}^{2}\right)$.

\section{Biochemical investigations}

Blood samples were obtained from each subject, and hemoglobin was measured (Sysmex SP-1000i, Sysmex American, Mundelein, IL, USA). After centrifugation, serum levels of blood urea nitrogen, creatinine, glucose, phosphorus, and C-reactive protein were measured by standard laboratory methods (Siemens Advia 1800, Siemens Healthcare GmbH, Henkestr, Germany). The fractional clearance index for urea $(\mathrm{Kt} / \mathrm{V})$ and urea reduction ratio (URR) was calculated using a formal, single-compartment dialysis urea kinetic model. Serum intact parathyroid hormone levels (iPTH) were 
determined with enzyme-linked immunosorbent assays (ELISA; Diagnostic Systems Laboratories, Webster, Texas, USA).

\section{Assessment of nutritional status}

Nutritional status was assessed by modified quantitative subjective global assessment (SGA), which included 7 variables: weight loss in the past 6 months, change in dietary intake, presence of gastrointestinal symptoms, change in functional capacity, comorbidities, subcutaneous loss of fat, and muscle wasting. Loss of subcutaneous fat was assessed over the triceps, biceps, and fat pads below the eyes, and muscle wasting was assessed on examination of the temples, clavicle and shoulder. Each component was assigned a score from 1 (normal) to 5 (very severe). A final score of 7-35 was assigned to each patient. A higher SGA score represents a more severe degree of malnutrition [25].

\section{Statistical analysis}

Continuous variables were presented as mean \pm standard deviation or as median and interquartile range, as appropriate. The Kolmogorov-Smirnov test was applied to test normality. The Student's independent $t$-test or the
Mann-Whitney U test were used for comparing continuous variables, according to the data distribution. Categorical variables were shown as absolute numbers with percentages and analyzed by chi-square test or Fisher's exact test. Correlations between HGS and continuous variables were analyzed by Pearson's or Spearman's rank correlation. Univariate and multivariate logistic regression were used to determine the factors associated with low HGS in chronic HD patients. Statistical analysis was performed using SPSS software (version 19.0; SPSS Inc., Chicago, IL, USA). A $P$-value of less than 0.05 was considered as statistically significant in all analyses.

\section{Results}

\section{Population characteristics}

Of 160 chronic HD patients screened, 120 cases met the inclusion criteria. Among them, 63 were male, and 57 were female. The mean age of the participants was 63.3 years, and $78(65.0 \%)$ patients had low HGS. The clinical and laboratory characteristics of patients with or without low HGS are presented in Table 1. Compared with the normal HGS group, patients with low HGS were older, weighed less, were shorter, and had lower skeletal muscle

Table 1 Clinical variables of the 120 hemodialysis patients with or without low handgrip strength

\begin{tabular}{|c|c|c|c|c|}
\hline Characteristics & All Patients $(n=120)$ & Normal HGS $(n=42)$ & Low HGS $(n=78)$ & $P$ \\
\hline Age (years) & $63.3 \pm 13.2$ & $55.0 \pm 10.1$ & $67.8 \pm 12.5$ & $<0.001^{*}$ \\
\hline HD duration (months) & $56.5(23.7-123.8)$ & $47.4(21.2-118.7)$ & $59.6(24.1-125.3)$ & 0.214 \\
\hline $\mathrm{SBP}(\mathrm{mmHg})$ & $142.6 \pm 27.1$ & $142.6 \pm 26.1$ & $142.6 \pm 27.8$ & 0.990 \\
\hline $\mathrm{DBP}(\mathrm{mmHg})$ & $77.5 \pm 16.6$ & $80.2 \pm 16.2$ & $76.0 \pm 16.8$ & 0.192 \\
\hline Height (cm) & $160.1 \pm 8.7$ & $164.0 \pm 9.8$ & $158.0 \pm 7.3$ & $0.001^{*}$ \\
\hline Post-HD body weight (kg) & $62.2 \pm 14.6$ & $66.8 \pm 16.0$ & $59.8 \pm 13.3$ & $0.018^{*}$ \\
\hline BMI $\left(\mathrm{kg} / \mathrm{m}^{2}\right)$ & $24.1 \pm 4.6$ & $24.6 \pm 4.5$ & $23.9 \pm 4.7$ & 0.436 \\
\hline $\mathrm{SMI}\left(\mathrm{kg} / \mathrm{m}^{2}\right)$ & $10.5(8.2-13.8)$ & $12.0(8.8-15.6)$ & $9.9(7.5-13.4)$ & $0.012^{*}$ \\
\hline Handgrip strength (kg) & $22.2 \pm 9.7$ & $31.1 \pm 7.7$ & $17.2 \pm 6.6$ & $<0.001^{*}$ \\
\hline Subjective global assessment & $13.5(10.0-17.0)$ & $11.0(10.0-14.0)$ & $14.0(11.0-18.0)$ & $0.002^{*}$ \\
\hline Hemoglobin (g/dl) & $10.4(9.7-11.1)$ & $10.5(9.6-11.2)$ & $10.4(9.9-11.0)$ & 0.789 \\
\hline Albumin (mg/dL) & $4.1(3.9-4.4)$ & $4.2(4.0-4.7)$ & $4.1(3.9-4.3)$ & 0.133 \\
\hline Glucose (mg/dL) & $129.0(106.3-166.8)$ & $123.0(100.0-143.5)$ & $131.5(110.0-174.0)$ & 0.058 \\
\hline Blood urea nitrogen (mg/dL) & $61.4 \pm 14.2$ & $64.0 \pm 13.5$ & $60.1 \pm 14.4$ & 0.150 \\
\hline Creatinine (mg/dL) & $9.6 \pm 2.0$ & $10.6 \pm 2.2$ & $9.1 \pm 1.8$ & $<0.001^{*}$ \\
\hline Phosphorus (mg/dL) & $4.7 \pm 1.3$ & $4.9 \pm 1.3$ & $4.7 \pm 1.3$ & 0.492 \\
\hline Intact parathyroid hormone $(\mathrm{pg} / \mathrm{mL})$ & $206.1(61.2-449.4)$ & $254.5(107.2-499.2)$ & $195.0(55.4-440.7)$ & 0.376 \\
\hline C-reactive protein (mg/dL) & $0.3(0.1-0.9)$ & $0.3(0.1-0.6)$ & $0.3(0.1-1.0)$ & 0.389 \\
\hline Kt/N (Gotch) & $1.34 \pm 0.17$ & $1.29 \pm 0.17$ & $1.36 \pm 0.17$ & $0.020^{*}$ \\
\hline URR & $0.73 \pm 0.04$ & $0.72 \pm 0.04$ & $0.74 \pm 0.04$ & $0.017^{*}$ \\
\hline
\end{tabular}

Values for continuous variables are given as means \pm standard deviation and were tested for significant differences by Student's $t$-test; variables not normally distributed are shown as medians and interquartile range and were tested by Mann-Whitney $\mathrm{U}$ test

$H G S$, handgrip strength; $H D$, hemodialysis; $S B P$, systolic blood pressure; $D B P$, diastolic blood pressure; $S M I$, skeletal muscle index; $K t / N$, fractional clearance index for urea; URR, urea reduction ratio

${ }^{*} P<0.05$ was considered statistically significant 
indexes, lower serum creatinine levels, and higher SGA scores, $\mathrm{Kt} / \mathrm{V}$ and URR.

Table 2 depicts a subgroup analysis of HD patients with and without low HGS. Among the 120 participants, $54(45.0 \%)$ patients were aged 65 years or older, 44 (36.7\%) patients had DM, and 57 (47.5\%) had hypertension. The patients in the low- HGS group were older and more of them had diabetes, while more patients in the normal HGS group took ARB. There were no differences in the distribution of gender; hypertension; or calcium channel blocker, $\beta$-blocker, statin, or fibrate use. No angiotensin-converting-enzyme inhibitor or renin inhibitor was consumed in our study population.

\section{Factors correlated with HGS}

The correlation between HGS and clinical variables in these HD patients, analyzed by Pearson's or Spearman's rank correlation test, is shown in Table 3. HGS was observed to be positively correlated with height $(r=0.653 ; P<0.001)$, post-HD body weight $(r=0.496$; $P<0.001)$, BMI $(r=0.215 ; P=0.020)$, SMI $(r=0.562$; $\mathrm{P}<0.001)$, albumin $(r=0.197 ; P=0.032)$, and serum creatinine $(r=0.544 ; P<0.001)$, while it was inversely correlated with age $(r=-0.506 ; P<0.001)$, SGA score $(r=-0.392 ; P<0.001), \mathrm{Kt} / \mathrm{V}(r=-0.404 ; P<0.001)$ and URR $(r=-0.459 ; P<0.001)$.

\section{Factors associated with low HGS}

Table 4 delineates the results of logistic regression analysis regarding the factors associated with low HGS. Univariate logistic regression analysis showed that age, height, post-HD body weight, ARB use, diabetes, SMI, $\mathrm{Kt} / \mathrm{V}$, and SGA score were significantly associated with the presence of low HGS. Multivariate logistic regression analysis showed that age (Odds ratio, OR $=1.11,95 \%$ confidence interval, 95\% CI $=1.05-1.17, P<0.001)$, HD duration $(\mathrm{OR}=1.01,95 \% \mathrm{CI}=1.00-1.02, P=0.010)$, diabetes $(\mathrm{OR}=13.33,95 \% \mathrm{CI}=3.45-51.53, P<0.001), \mathrm{Kt} / \mathrm{V}$ $(\mathrm{OR}=1.61,95 \% \mathrm{CI}=1.06-2.46, \quad P=0.027)$, and $\mathrm{SGA}$ score $(\mathrm{OR}=1.19,95 \% \mathrm{CI}=1.03-1.38, P=0.017)$ were independently associated with low HGS. Meanwhile, ARB use $(\mathrm{OR}=0.25,95 \% \mathrm{CI}=0.07-0.93, P=0.039)$ was found to be independently related to preserved HGS in HD patients, after adjustment for age, gender, height, post-HD body weight, HD duration, diabetes, SMI, Kt/V, and SGA score. Thus, our patients with ARB use showed a $75 \%$ decreased odds in handgrip strength weakness, when compared with patients without ARB use.

\section{Discussion}

In this cross-sectional study, nearly two-thirds $(65.0 \%)$ of our chronic HD patients were demonstrated to have low HGS, according to the EWGSOP definition. Height, weight, BMI, SMI, albumin, and serum creatinine were found to be positively correlated with

Table 2 Distribution of hemodialysis patients with or without low handgrip strength in subgroup analysis

\begin{tabular}{|c|c|c|c|c|}
\hline Characteristics & & Normal HGS group (\%) & Low HGS group (\%) & $P$ \\
\hline \multirow[t]{2}{*}{ Old age ( $\geq 65$ years) } & No & $36(85.7)$ & $30(38.5)$ & $<0.001^{*}$ \\
\hline & Yes & $6(14.3)$ & $48(61.5)$ & \\
\hline \multirow[t]{2}{*}{ Gender } & Male & $26(61.9)$ & $37(47.4)$ & 0.130 \\
\hline & Female & $16(38.1)$ & $41(52.6)$ & \\
\hline \multirow[t]{2}{*}{ Diabetes } & No & $34(81.0)$ & $42(53.8)$ & $0.003^{*}$ \\
\hline & Yes & $8(19.0)$ & $36(46.2)$ & \\
\hline \multirow[t]{2}{*}{ Hypertension } & No & $18(42.9)$ & $45(57.7)$ & 0.121 \\
\hline & Yes & $24(57.1)$ & $33(42.3)$ & \\
\hline \multirow[t]{2}{*}{ ARB use } & No & $24(57.1)$ & $61(78.2)$ & $0.015^{*}$ \\
\hline & Yes & $18(42.9)$ & $17(21.8)$ & \\
\hline \multirow[t]{2}{*}{ CCB use } & No & $20(47.6)$ & $51(65.4)$ & 0.059 \\
\hline & Yes & $22(52.4)$ & 27 (34.6) & \\
\hline \multirow[t]{2}{*}{$\beta$-blocker use } & No & $26(61.9)$ & $58(74.4)$ & 0.156 \\
\hline & Yes & $16(38.1)$ & $20(25.6)$ & \\
\hline \multirow[t]{2}{*}{ Statin use } & No & $39(92.9)$ & $64(82.1)$ & 0.105 \\
\hline & Yes & $3(7.1)$ & $14(17.9)$ & \\
\hline \multirow[t]{2}{*}{ Fibrate use } & No & $36(85.7)$ & $68(87.2)$ & 0.822 \\
\hline & Yes & $6(14.3)$ & $10(12.8)$ & \\
\hline
\end{tabular}

Data are expressed as number of patients, and analysis was performed using the chi-square test or Fisher's exact test ARB, angiotensin II receptor blockers; CCB, calcium channel blockers 
Table 3 Correlation between HGS and clinical variables among 120 hemodialysis patients

\begin{tabular}{|c|c|c|}
\hline \multirow[t]{2}{*}{ Variables } & \multicolumn{2}{|l|}{$\mathrm{HGS}(\mathrm{kg})$} \\
\hline & $r$ & $P$ \\
\hline Age (years) & -0.506 & $<0.001^{*}$ \\
\hline HD duration (months) ${ }^{a}$ & -0.144 & 0.120 \\
\hline Height (cm) & 0.653 & $<0.001^{*}$ \\
\hline Post-HD body weight (kg) & 0.496 & $<0.001^{*}$ \\
\hline $\mathrm{BMI}\left(\mathrm{kg} / \mathrm{m}^{2}\right)$ & 0.215 & $0.020^{*}$ \\
\hline SMI $\left(\mathrm{kg} / \mathrm{m}^{2}\right)^{\mathrm{a}}$ & 0.562 & $<0.001^{*}$ \\
\hline$S G A^{a}$ & -0.392 & $<0.001^{*}$ \\
\hline Hemoglobin $(\mathrm{g} / \mathrm{dl})^{a}$ & 0.022 & 0.811 \\
\hline Albumin $(\mathrm{mg} / \mathrm{dL})^{a}$ & 0.197 & $0.032^{*}$ \\
\hline Glucose $(\mathrm{mg} / \mathrm{dL})^{\mathrm{a}}$ & -0.126 & 0.173 \\
\hline Creatinine (mg/dL) & 0.544 & $<0.001^{*}$ \\
\hline Phosphorus (mg/dL) & 0.059 & 0.527 \\
\hline Intact parathyroid hormone $(\mathrm{pg} / \mathrm{mL})^{a}$ & 0.009 & 0.919 \\
\hline$C$ reactive protein $(\mathrm{mg} / \mathrm{dL})^{a}$ & -0.044 & 0.637 \\
\hline Kt/N (Gotch) & -0.404 & $<0.001^{*}$ \\
\hline URR $^{\mathrm{a}}$ & -0.459 & $<0.001^{*}$ \\
\hline
\end{tabular}

HGS, handgrip strength; HD, hemodialysis; SMI, skeletal muscle index; Kt/V, fractional clearance index for urea;

URR, urea reduction ratio

${ }^{\text {a } T h e ~ d a t a ~ s h o w e d ~ a ~ s k e w e d ~ d i s t r i b u t i o n ~ a n d ~ w e r e ~ a n a l y z e d ~ b y ~ S p e a r m a n ' s ~}$ correlation analysis

${ }^{*} P<0.05$ was considered statistically significant

HGS, while age, SGA score, and Kt/V were negatively correlated with HGS. After multivariable adjustment, age, HD duration, diabetes, Kt/V, and SGA score remained as independent predictors of low HGS. More interestingly, a significantly higher proportion of chronic HD patients with preserved HGS took ARBs, and this association persisted after adjustment for multiple confounding factors.
Angiotensin II overexpression was known to not only increase the catabolic effects on skeletal muscle by inhibiting the Akt/mammalian target of rapamycin (mTOR) pathway but also to induce skeletal muscle protein degradation through reactive oxygen species accumulation, which in turn activates nuclear factor kappa B (NF-kB) and p38MAPK (p38 mitogen-activated protein kinase) [16]. Losartan had been demonstrated to reduce muscle fibrosis and to improve muscle function after cardiotoxin-induced muscle injury by modulation of TGF- $\beta$ pathway and also to protect against loss of muscle mass in treated immobilized mice, an effect mediated by increased activation of the Akt/mTOR pathway [22]. Bedair et al. showed that losartan-treated mice exhibited a dose-dependent enhancement of muscle healing and muscle regeneration after laceration injury [20]. Furthermore, treatment with irbesartan after cryoinjury also improves muscle repair and regeneration through suppression of the $\mathrm{C} 1 \mathrm{q}-\mathrm{Wnt} / \beta$-catenin signaling pathway [18]. Despite cumulative evidence provided by animal studies, whether ARB use has a protective effect on skeletal muscle in humans is largely unknown. To the best of our knowledge, this association between ARB use and preserved muscle strength in ESRD patients has not yet been reported. We found that ARB use in our chronic HD patients could reveal a $75 \%$ decreased odds in handgrip weakness, when compared with patients who did not use ARB. Although this finding appears to be prominent and promising, an unmeasured confounding bias is still possible. Further studies are encouraged to evaluate whether ARB use protects against muscle strength loss in chronic HD patients.

Besides age and sex, comorbidities and nutritional status were well known to be associated with muscle strength in patients with ESRD [26-31]. In our study, the presence of DM is the major predictor of low

Table 4 Logistic regression analysis of the factors correlated with low handgrip strength in 120 hemodialysis patients

\begin{tabular}{|c|c|c|c|c|}
\hline \multirow[t]{2}{*}{ Variable } & \multicolumn{2}{|l|}{ Univariate } & \multicolumn{2}{|l|}{ Adjusted } \\
\hline & OR $(95 \% \mathrm{Cl})$ & $P$ & OR $(95 \% \mathrm{Cl})$ & $P$ \\
\hline Age (years) & $1.10(1.05-1.14)$ & $<0.001^{*}$ & $1.11(1.05-1.17)$ & $<0.001^{*}$ \\
\hline Female & $1.80(0.84-3.87)$ & 0.132 & $0.42(0.07-2.44)$ & 0.336 \\
\hline Height (cm) & $0.92(0.87-0.96)$ & $0.001^{*}$ & $0.94(0.84-1.06)$ & 0.327 \\
\hline Post-HD body weight (kg) & $0.97(0.94-0.99)$ & $0.015^{*}$ & $1.03(0.92-1.16)$ & 0.590 \\
\hline HD duration (months) & $1.00(1.00-1.01)$ & 0.234 & $1.01(1.00-1.02)$ & $0.010^{*}$ \\
\hline ARB use & $0.37(0.17-0.84)$ & $0.017^{*}$ & $0.25(0.07-0.93)$ & $0.039^{*}$ \\
\hline Diabetes & $3.64(1.50-8.87)$ & $0.004^{*}$ & $13.33(3.45-51.53)$ & $<0.001^{*}$ \\
\hline SMI $\left(\mathrm{kg} / \mathrm{m}^{2}\right)$ & $0.91(0.83-0.99)$ & $0.029^{*}$ & $0.98(0.66-1.45)$ & 0.917 \\
\hline Kt/N (per 0.1 increment) & $1.34(1.04-1.73)$ & $0.023^{*}$ & $1.61(1.06-2.46)$ & $0.027^{*}$ \\
\hline SGA & $1.14(1.04-1.26)$ & $0.008^{*}$ & $1.19(1.03-1.38)$ & $0.017^{*}$ \\
\hline
\end{tabular}

${ }^{*} P<0.05$ is considered statistically significant in univariate and multivariate logistic regression analysis (adopted factors: age, gender, height, post-HD body weight, $\mathrm{HD}$ duration, $\mathrm{ARB}$ use, diabetes, SMI, $\mathrm{Kt} / \mathrm{V}$, and SGA)

$\mathrm{HD}$, hemodialysis; ARB, angiotensin II receptor blockers; SMI, skeletal muscle index, Kt/V, fractional clearance index for urea; SGA, subjective global assessment 
handgrip strength, which was consistent with the findings of previous studies. DM is associated with accelerated muscle weakness due to rapid skeletal muscle protein breakdown contributed by insulin resistance and increased levels of inflammatory cytokines. Moreover, diabetic neuropathy also has major negative impacts on HGS [28, 32]. Our data showed that low handgrip strength was associated with poor nutrition status, which was also confirmed by other studies [30,31]. In addition, both Silva et al. and Wang et al. regarded HGS as an indicator of nutritional status in dialysis patients [29, 33].

Our result showed that both HD duration and $\mathrm{Kt} / \mathrm{V}$ were negatively associated with muscle strength. However, a correlation between HGS and $\mathrm{Kt} / \mathrm{V}$ was not found in other studies [30,34]. Dialysis treatment per se has been shown to stimulate protein degradation and increase nitrogen losses [35, 36]. In addition, several studies consistently showed that hemodialysis leads to an increase in skeletal muscle net protein catabolism [3739], which may partially explain our finding. Meanwhile, patients with malnutrition and small body size can contribute to an overestimation of $\mathrm{Kt} / \mathrm{V}$ other than dialysis exposure per se. Therefore, high Kt/V in the study might actually imply the small body size or malnutrition status of our patients. Indeed, extremely high $\mathrm{Kt} / \mathrm{V}$ was observed to be associated with increased mortality in dialysis patients [40, 41]. Unfortunately, standardized creatinine clearance, which was corrected for body surface area, was not available in our study. Further longitudinal studies are needed to clarify the impact of delivered dialysis dose on muscle strength loss.

There are several limitations to our study. First, our sample size was relatively small. Second, the normal value of HGS in the ESRD population remains to be established. The diagnostic criteria for low muscle strength in the geriatric population were adopted in this study; however, whether this cut-off for HGS could be applied to patients with ESRD has not been validated. Finally, a causal relationship cannot be obtained from this cross-sectional study, and our result should be regarded as hypothesis generating.

\section{Conclusions}

We conclude that age, HD duration, diabetes, $\mathrm{Kt} / \mathrm{V}$, and SGA score are independent predictors of low HGS, while ARB use is reported for the first time to be associated with preserved HGS in chronic HD patients. However, longitudinal observational follow-up and intervention studies are needed to clarify the role of ARB use in the maintenance of skeletal muscle strength and mass in dialysis patients.

\section{Abbreviations}

ARB: angiotensin II receptor blocker; BMl: body mass index; DM: diabetes; ESRD: end-stage renal disease; EWGSOP: European Working Group on Sarcopenia in Older People; HD: hemodialysis; HGS: handgrip strength;
iPTH: intact parathyroid hormone; Kt $\mathrm{N}$ : fractional clearance index for urea; mTOR: mammalian target of rapamycin; NF-kB: nuclear factor kappa B; p38MAPK: p38 mitogen-activated protein kinase; SGA: subjective global assessment; SMI: skeletal muscle index

\section{Acknowledgements}

None.

\section{Funding}

The study was supported by a grant from the Buddhist Tzu Chi General Hospital, Hualien, Taiwan (TCRD105-04, support study design and collection of data).

\section{Availability of data and materials}

The dataset used and/or analyzed during the current study are available from the corresponding author on reasonable request.

\section{Authors' contributions}

Y.-L. L., H.-H. L., and B.-G. H. conceived and designed the experiments; C.-H. W., Y.-H. L., and C.-H. K. performed the experiments; Y.-L. L. and S.-Y. C. analyzed the data; Y.-L. L. and B.-G. H. contributed reagents; Y.-L. L., H.-H. L., and B.-G. H. wrote the paper. All authors have read and approved the manuscript.

Ethics approval and consent to participate

All participants signed an informed consent approved by the Institutional Review Board of Tzu Chi Hospital.

Consent for publication

Not applicable.

Competing interests

The authors declare that they have no competing interests.

\section{Publisher's Note}

Springer Nature remains neutral with regard to jurisdictional claims in published maps and institutional affiliations.

\section{Author details}

${ }^{1}$ Division of Nephrology, Buddhist Tzu Chi General Hospital, Hualien, Taiwan. ${ }^{2}$ Department of Public Health, Tzu Chi University, Hualien, Taiwan. ${ }^{3}$ Division of Nephrology, Department of Internal Medicine, Hsin-Jen Hospital, New

Taipei City, Taiwan. ${ }^{4}$ School of Medicine, Tzu Chi University, Hualien, Taiwan.

Received: 29 June 2018 Accepted: 22 January 2019

Published online: 14 February 2019

\section{References}

1. Landi F, Cruz-Jentoft AJ, Liperoti R, Russo A, Giovannini S, Tosato M, Capoluongo E, Bernabei R, Onder G. Sarcopenia and mortality risk in frail older persons aged 80 years and older: results from ilSIRENTE study. Age Ageing. 2013;42(2):203-9.

2. Arango-Lopera $V$, Arroyo P, Gutiérrez-Robledo LM, Perez-Zepeda M, Cesari M Mortality as an adverse outcome of sarcopenia. J Nutr Health Aging. 2013; 17(3):259.

3. Kim JH, Lim S, Choi SH, Kim KM, Yoon JW, Kim KW, Lim J-Y, Park KS, Jang HC, Kritchevsky S. Sarcopenia: an independent predictor of mortality in community-dwelling older Korean men. J Gerontol A Biol Sci Med Sci. 2014;69(10):1244-52.

4. Cruz-Jentoft AJ, Baeyens JP, Bauer JM, Boirie Y, Cederholm T, Landi F, Martin FC, Michel JP, Rolland Y, Schneider SM, et al. Sarcopenia: European consensus on definition and diagnosis: report of the European working group on sarcopenia in older people. Age Ageing. 2010;39(4):412-23.

5. Kim JK, Choi SR, Choi MJ, Kim SG, Lee YK, Noh JW, Kim HJ, Song YR. Prevalence of and factors associated with sarcopenia in elderly patients with end-stage renal disease. Clin Nutr. 2014;33(1):64-8.

6. Lamarca F, Carrero JJ, Rodrigues JC, Bigogno FG, Fetter RL, Avesani CM. Prevalence of sarcopenia in elderly maintenance hemodialysis patients: the impact of different diagnostic criteria. J Nutr Health Aging. 2014;18(7):710-7. 
7. Ren H, Gong D, Jia F, Xu B, Liu Z. Sarcopenia in patients undergoing maintenance hemodialysis: incidence rate, risk factors and its effect on survival risk. Ren Fail. 2016;38(3):364-71.

8. Isoyama N, Qureshi AR, Avesani CM, Lindholm B, Bàràny $P$, Heimbürger $O$, Cederholm T, Stenvinkel P, Carrero JJ. Comparative associations of muscle mass and muscle strength with mortality in Dialysis patients. Clin J Am Soc Nephrol. 2014;9(10):1720-8

9. Goodpaster BH, Park SW, Harris TB, Kritchevsky SB, Nevitt M, Schwartz AV, Simonsick EM, Tylavsky FA, Visser M, Newman AB. The loss of skeletal muscle strength, mass, and quality in older adults: the health, aging and body composition study. J Gerontol A Biol Sci Med Sci. 2006;61(10):1059-64.

10. Kittiskulnam P, Chertow GM, Carrero JJ, Delgado C, Kaysen GA, Johansen KL. Clinical investigation: sarcopenia and its individual criteria are associated, in part, with mortality among patients on hemodialysis. Kidney Int. 2017;92: 238-47

11. Matos CM, Silva LF, Santana LD, Santos LS, Protásio BM, Rocha MT, Ferreira VL, Azevedo MF, Martins MTS, Lopes GB, et al. Handgrip strength at baseline and mortality risk in a cohort of women and men on hemodialysis: a 4-year study. J Ren Nutr. 2014;24(3):157-62.

12. Vogt $B P$, Borges MC, Goes CR, Caramori JC. Handgrip strength is an independent predictor of all-cause mortality in maintenance dialysis patients. Clin Nutr. 2016;35(6):1429-33.

13. Yoda M, Inaba M, Okuno S, Yoda K, Yamada S, Imanishi Y, Mori K, Shoji T, Ishimura E, Yamakawa T, et al. Poor muscle quality as a predictor of high mortality independent of diabetes in hemodialysis patients. Biomed Pharmacother. 2012;66(4):266-70.

14. Fahal $I H$. Uraemic sarcopenia: aetiology and implications. Nephrol Dial Transplant. 2013

15. Delafontaine $P$, Yoshida $T$. The renin-angiotensin system and the biology of skeletal muscle: mechanisms of muscle wasting in chronic disease states. Trans Am Clin Climatol Assoc. 2016;127:245-58.

16. Cabello-Verrugio C, Morales MG, Rivera JC, Cabrera D, Simon F. Reninangiotensin system: an old player with novel functions in skeletal muscle. Med Res Rev. 2015;35(3):437-63.

17. Song Y-H, Li Y, Du J, Mitch WE, Rosenthal N, Delafontaine P. Muscle-specific expression of IGF-1 blocks angiotensin II-induced skeletal muscle wasting. J Clin Investig. 2005;115(2):451-8.

18. Yabumoto $C$, Akazawa $H$, Yamamoto $R$, Yano M, Kudo-Sakamoto $Y$, Sumida T, Kamo T, Yagi H, Shimizu Y, Saga-Kamo A, et al. Angiotensin II receptor blockade promotes repair of skeletal muscle through down-regulation of aging-promoting C1q expression. Sci Rep. 2015;5:14453.

19. Kobayashi M, Ota S, Terada S, Kawakami Y, Otsuka T, Fu FH, Huard J. The combined use of losartan and muscle-derived stem cells significantly improves the functional recovery of muscle in a young mouse model of contusion injuries. Am J Sports Med. 2016:44(12):3252-61.

20. Bedair HS, Karthikeyan T, Quintero A, Li Y, Huard J. Angiotensin II receptor blockade administered after injury improves muscle regeneration and decreases fibrosis in normal skeletal muscle. Am J Sports Med. 2008;36(8): 1548-54.

21. Cabello-Verrugio C, Morales MG, Cabrera D, Vio CP, Brandan E. Angiotensin II receptor type 1 blockade decreases CTGF/CCN2-mediated damage and fibrosis in normal and dystrophic skeletal muscles. J Cell Mol Med. 2012; 16(4):752-64.

22. Burks TN, Andres-Mateos E, Marx R, Mejias R, Van Erp C, Simmers JL, Walston JD, Ward CW, Cohn RD: Losartan restores skeletal muscle remodeling and protects against disuse atrophy in sarcopenia. Sci Transl Med 2011, 3(82): 82ra37-82ra37.

23. Leal VO, Mafra D, Fouque D, Anjos LA. Use of handgrip strength in the assessment of the muscle function of chronic kidney disease patients on dialysis: a systematic review. Nephrol Dial Transplant. 2011;26(4):1354-60.

24. Rodrigues J, Cuppari L, Campbell KL, Avesani CM. Nutritional assessment of elderly patients on dialysis: pitfalls and potentials for practice. Nephrol Dial Transplant. 2017;32(11):1780-9.

25. Kalantar-Zadeh K, Kleiner M, Dunne E, Lee GH, Luft FC. A modified quantitative subjective global assessment of nutrition for dialysis patients. Nephrol Dial Transplant. 1999;14(7):1732-8.

26. Pinto AP, Ramos Cl, Meireles MS, Kamimura MA, Cuppari L. Impact of hemodialysis session on handgrip strength. J Bras Nefrol. 2015;37(4):451-7.

27. Balducci S, Sacchetti M, Orlando G, Salvi L, Pugliese L, Salerno G, D'Errico V, lacobini $\mathrm{C}$, Conti FG, Zanuso $S$, et al. Correlates of muscle strength in diabetes: the study on the assessment of determinants of muscle and bone strength abnormalities in diabetes (SAMBA). Nutr Metab Cardiovasc Dis. 2014;24(1):18-26.

28. Noori N, Kopple JD: Effect of diabetes mellitus on protein-energy wasting and protein wasting in end-stage renal disease. In: Seminars in dialysis: 2010: Wiley online library; 2010: 178-184.

29. Wang AY, Sea MM, Ho ZS, Lui SF, Li PK, Woo J. Evaluation of handgrip strength as a nutritional marker and prognostic indicator in peritoneal dialysis patients. Am J Clin Nutr. 2005;81(1):79-86.

30. Qureshi AR, Alvestrand A, Danielsson A, Divino-Filho JC, Gutierrez A Lindholm B, Bergstrom J. Factors predicting malnutrition in hemodialysis patients: a cross-sectional study. Kidney Int. 1998;53(3):773-82.

31. Stenvinkel $P$, Barany $P$, Chung SH, Lindholm B, Heimburger O. A comparative analysis of nutritional parameters as predictors of outcome in male and female ESRD patients. Nephrol Dial Transplant. 2002;17(7):1266-74.

32. Park SW, Goodpaster BH, Strotmeyer ES, Kuller LH, Broudeau R, Kammerer C, de Rekeneire N, Harris TB, Schwartz AV, Tylavsky FA et al: Accelerated Loss of Skeletal Muscle Strength in Older Adults With Type 2 Diabetes. The Health, Aging, and Body Composition Study 2007, 30(6):1507-1512.

33. Silva LF, Matos CM, Lopes GB, Silveira Martins MT, Martins MS, Arias LU, Pisoni RL, Lopes AA. Handgrip strength as a simple Indicator of possible malnutrition and inflammation in men and women on maintenance hemodialysis. J Ren Nutr. 2011;21(3):235-45.

34. Leal VO, Stockler-Pinto MB, Farage NE, Aranha LN, Fouque D, Anjos LA, Mafra D. Handgrip strength and its dialysis determinants in hemodialysis patients. Nutrition. 2011;27(11-12):1125-9.

35. Lim VS, Ikizler TA, Raj DS, Flanigan MJ. Does hemodialysis increase protein breakdown? Dissociation between whole-body amino acid turnover and regional muscle kinetics. J Am Soc Nephrol. 2005;16(4):862-8.

36. Pupim LB, Majchrzak KM, Flakoll PJ, Ikizler TA. Intradialytic oral nutrition improves protein homeostasis in chronic hemodialysis patients with deranged nutritional status. J Am Soc Nephrol. 2006;17(11):3149-57.

37. Ikizler TA, Pupim LB, Brouillette JR, Levenhagen DK, Farmer K, Hakim RM, Flakoll PJ. Hemodialysis stimulates muscle and whole body protein loss and alters substrate oxidation. Am J Physiol Endocrinol Metab. 2002;282(1):E107-16.

38. Raj DSC, Dominic EA, Wolfe R, Shah VO, Bankhurst A, Zager PG, Ferrando A. Coordinated increase in albumin, fibrinogen, and muscle protein synthesis during hemodialysis: role of cytokines. Am J Physiol Endocrinol Metabol. 2004;286(4):E658-64

39. Pupim LB, Flakoll PJ, Brouillette JR, Levenhagen DK, Hakim RM, Ikizler TA. Intradialytic parenteral nutrition improves protein and energy homeostasis in chronic hemodialysis patients. J Clin Invest. 2002;110(4):483-92.

40. Salahudeen AK, Dykes P, May W. Risk factors for higher mortality at the highest levels of spKt $N$ in haemodialysis patients. Nephrol Dial Transplant. 2003;18(7):1339-44.

41. Chertow GM, Owen WF, Lazarus JM, Lew NL, Lowrie EG. Exploring the reverse J-shaped curve between urea reduction ratio and mortality. Kidney Int. 1999;56(5):1872-8.

\section{Ready to submit your research? Choose BMC and benefit from:}

- fast, convenient online submission

- thorough peer review by experienced researchers in your field

- rapid publication on acceptance

- support for research data, including large and complex data types

- gold Open Access which fosters wider collaboration and increased citations

- maximum visibility for your research: over $100 \mathrm{M}$ website views per year

At BMC, research is always in progress.

Learn more biomedcentral.com/submissions 